\title{
Comparison of space analysis performed on plaster vs. digital dental casts applying Tanaka and Johnston's equation
}

\author{
Júlia Olien Sanches¹, Lourdes Aparecida Martins dos Santos-Pinto², \\ Ary dos Santos-Pinto ${ }^{3}$, Betina Grehs ${ }^{1}$ Fabiano Jeremias ${ }^{4}$
}

Objective: The purpose of this study was to compare dental size measurements, their reproducibility and the application of Tanaka and Johnston regression equation in predicting the size of canines and premolars on plaster and digital dental casts. Methods: Thirty plaster casts were scanned and digitized. Mesiodistal measurements of the teeth were then performed with a digital caliper on the plaster and digital casts using $\mathrm{O} 3 \mathrm{~d}$ software system (Widialabs ${ }^{\odot}$ ). The sum of the sizes of the lower incisors was used to obtain predictive values of the sizes of the premolars and canines using the regression equation, and these values were compared with the actual sizes of the teeth. The data were statistically analyzed by applying to the results Pearson's correlation test, Dahlberg's formula, paired t-test and analysis of variance $(p<0.05)$. Results: Excellent intraexaminer agreement was observed in the measurements performed on both dental casts. No random error was present in the measurements obtained with the caliper and systematic error (bias) was more frequent in the digital casts. Space prediction obtained by applying the regression equation was greater than the sum of the canines and premolars on the plaster and digital casts. Conclusions: Despite an adequate reproducibility of the measurements performed on both casts, most measurements on the digital casts were higher than those on the plaster casts. The predicted space was overestimated in both models and significantly higher in the digital casts.

Keywords: Three-dimensional image. Dental casts. Test reproducibility.

Objetivo: comparar medidas de tamanhos dentários, suas reprodutibilidades e a aplicação da equação de regressão de Tanaka e Johnston na predição do tamanho dos caninos e pré-molares em modelos de gesso e digital. Métodos: trinta modelos de gesso foram escaneados para obtenção dos modelos digitais. As medidas do comprimento mesiodistal dos dentes foram obtidas com paquímetro digital nos modelos de gesso e nos modelos digitais utilizando o software O3d (Widialabs). A somatória do tamanho dos incisivos inferiores foi utilizada para obter os valores de predição do tamanho dos pré-molares e caninos utilizando equação de regressão, e esses valores foram comparados ao tamanho real dos dentes. Os dados foram analisados estatisticamente, aplicando-se aos resultados o teste de correlação de Pearson, a fórmula de Dahlberg, o teste $t$ pareado e a análise de variância $(\mathrm{p}<0,05)$. Resultados: excelente concordância intraexaminador foi observada nas medidas realizadas em ambos os modelos. $\mathrm{O}$ erro aleatório não esteve presente nas medidas obtidas com paquímetro, e o erro sistemático foi mais frequente no modelo digital. A previsão de espaço obtida pela aplicação da equação de regressão foi maior que a somatória dos pré-molares e caninos presentes nos modelos de gesso e nos modelos digitais. Conclusão: apesar da boa reprodutibilidade das medidas realizadas em ambos os modelos, a maioria das medidas dos modelos digitais foram superiores às do modelos de gesso. O espaço previsto foi superestimado em ambos os modelos e significativamente maior nos modelos digitais.

Palavras-chave: Imagem Tridimensional. Modelos dentários. Reprodutibilidade dos testes.

${ }^{1}$ Undergraduate student, Araraquara Dental School, São Paulo State University (UNESP).

${ }^{2}$ Full Professor, Children's Clinic Department, Araraquara Dental School (UNESP).

${ }^{3}$ Associate Professor, Children's Clinic Department, Araraquara Dental School (UNESP).

${ }^{4}$ Graduate student, Araraquara Dental School (UNESP).

Submitted: September 28, 2010 - Revised and accepted: November 08, 2011
How to cite this article: Sanches JO, Santos-Pinto LAM, Santos-Pinto A, Grehs B, Jeremias F. Comparison of space analysis performed on plaster vs. digital dental casts applying Tanaka and Johnston's equation. Dental Press J Orthod. 2013 Jan-Feb;18(1):128-33.

" The authors report no commercial, proprietary or financial interest in the products or companies described in this article.

Contact address: Lourdes Aparecida Martins dos Santos-Pinto Rua Humaitá, 1680 - Araraquara/SP

CEP: 14801-930 - Email: 1spinto@foar.unesp.br 


\section{INTRODUCTION}

Determining the mesiodistal size of unerupted permanent teeth is an important procedure in the diagnosis and treatment planning of patients in the mixed dentition as it is instrumental in predicting the required space in the dental arch where the teeth - usually canines and premolars - will be positioned.

Some methods use the adequate correlation found between the width of the permanent lower incisors and unerupted canines and premolars to predict space in mixed dentition. One such example is Moyer's analysis. ${ }^{1}$ Space prediction in mixed dentition can also be carried out using regression equations for each side of the upper $[\mathrm{Y}=11+0.5(\mathrm{X})]$ and lower $[\mathrm{Y}=10.5+0.5(\mathrm{X})]$ dental arches, where $\mathrm{Y}$ is the sum of the unerupted canines and premolars and $\mathrm{X}$ the sum of the four unerupted permanent incisors. ${ }^{2}$ This analysis is considered one of the most practical for clinical use as it requires no $\mathrm{x}$-rays or tables to predict the size of the teeth. ${ }^{1}$

Traditionally, these diagnostic tests have been performed on plaster casts, where one can (a) assess the occlusal relationships of patients without interfering with soft tissues, (b) determine the issues to be addressed and (c) define which orthodontic mechanics will be applied. However, some of the disadvantages inherent in the use of plaster casts ${ }^{3,4}$ are their weight and volume, time spent on their fabrication, the need for a physical storage space, the risk of breakage and difficulty in exchanging information with other professionals. Currently, digital casts offer orthodontists a convenient alternative to routine plaster casts. Their greater attractiveness is related to the speed to store patient diagnoses in a computer, instant accessibility and convenient sharing of information with colleagues. ${ }^{5}$ A variety of methods have been developed to digitize plaster casts. Digitization is performed on casts or alginate impressions with the aid of a scanner or digital camera. The software used can electronically store the images and perform three-dimensional measurements. ${ }^{4,6,7}$ Digital casts can be overviewed in a $360^{\circ}$ view, in all planes of space, and can also be viewed singly, i.e., only the upper or only the lower dental arch. ${ }^{5}$ Most digital image analysis software available on the market are not developed in Brazil, which results in high costs since patient impressions or plaster casts must be shipped overseas for scanning. O3d is a software system developed by Widialabs ${ }^{\odot}$ (Goiânia, Brazil), a pioneering Brazilian company in the development of technologies geared to the digitization and analysis of dental casts for use in orthodontics. Orthodontists can access their digitized casts on the company's website, download these data to their computer and perform measurements and analyses.

Recent studies show that measurements of dental arch sizes, arch width, overjet and overbite on digital models are valid and can be reproduced..$^{8,9}$ Measuring tooth size on the arch itself is influenced by several factors such as tooth inclination, rotation, proximal contact, anatomical variations and interexaminer variability. Thus, the accuracy and reliability of these software need to be evaluated prior to clinical implementation. ${ }^{10}$ Within the context outlined above, the aim of this study was to compare the measurements of dental sizes, their reproducibility and prediction of the sizes of the upper and lower canines and premolars by applying Tanaka and Johnston' ${ }^{2}$ regression equation on plaster dental casts and digital models.

\section{MATERIAL AND METHODS}

After approval by the Ethics Committee of Araraquara Dental School (UNESP) (Protocol \#33/07) thirty plaster casts were selected from the diagnostic records of patients that were receiving treatment with fixed appliances. All casts were scanned in the Orthodontic Records Service (SDO) in Araraquara, São Paulo State, and standardized by the same professional.

The criteria for inclusion of plaster casts in the study were: Presence of incisors, canines, premolars and permanent first molars in both the maxillary and mandibular arches; all cast teeth showing normal morphology; absence of irregularities in the plaster caused by carious lesions and restorations, which might affect the mesiodistal or buccolingual diameter of dental crowns; no prior orthodontic treatment.

The models were replicated to prevent damage to the patient records. The impressions were taken by the same professional using plastic trays (Morelli Orthodontics, Sorocaba, SP, Brazil) and alginate (Jeltrate, Dentsply, Petrópolis, RJ, Brazil).The casts were fabricated with special dental stone (Durone V, Dentsply, Petrópolis, RJ, Brazil) vacuum mixed at a ratio of $19 \mathrm{ml}$ water to $100 \mathrm{~g}$ of powder and poured onto a vibrator to decrease the likelihood of bubbles.

Two casts were used as standard and had 12 points marked on their upper arch and 20 points on their 
lower arch as reference for the largest mesiodistal diameter of the crowns of the maxillary and mandibular canines and premolars, and mandibular incisors. Ten casts were randomly selected to be measured with a digital caliper (Mitutoyo Digimatic ${ }^{\circledR}$, Mitutoyo Ltd., Suzano, SP, Brazil). The measurements were repeated within a one-week interval for examiner calibration. Reliability of the variable measuring process was evaluated by Pearson's correlation coefficient, which was 0.96 .

After calibration, the measurements reflecting the greatest distance between the mesial and distal surfaces of crowns of all mandibular teeth and of all maxillary canines and premolars were obtained using a digital caliper. In the posterior teeth, these distances were obtained with an occlusal view of the model, and in anterior teeth, with a labial view.

Once the measurements with the digital caliper were completed, the models were forwarded for non-destructive laser scanning, with the reading done by surface scanning using a R-700 Orthodontic 3D Scanner (Copenhagen, Denmark) without touching the cast, and with an accuracy of 0.005 -in and 400 dots per inch (DPI). Using O3d software (Widialabs, Goiânia, Brazil) with three-dimensional images, measurements were carried out by drawing a transverse line across the largest mesiodistal width of the posterior teeth examined in occlusal view and labial view of the anterior teeth as described in the literature. ${ }^{6,9,11,12}$

Teeth prediction values calculated by applying Tana$\mathrm{ka}$ and Johnston's ${ }^{2}$ regression equation were compared to the actual sizes of maxillary and mandibular premolars and canines measured directly on the plaster models and three-dimensional images. All measurements were repeated within a one-week interval to test intraexaminer reliability, confirmed by Pearson's correlation test. Dahlberg's formula was applied to estimate the magnitude of casual errors and the paired t-test was applied to identify systematic errors, according to Houston. ${ }^{13}$ The difference between the measurements obtained in the plaster vs. digital casts was evaluated by means of analysis of variance at a 5\% significance level $(p<0.05)$.

\section{RESULTS}

Assessment of intraexaminer reliability was performed for all dental measurements and in all models, yielding an excellent correlation between the first and second measurements performed both using a caliper on the plaster casts and the O3d software system on digital models. Application of Dahlberg's formula showed no random error in measurements performed with a caliper on the plaster casts. Systematic error was found only in the measurements of teeth 24 and 43, which showed a difference of one hundredth of a millimeter (-0.06 and $-0.05 \mathrm{~mm}$, respectively), considered clinically insignificant. The measurements carried out on digital casts using the O3d System showed random error in teeth 13, 23 and 33. In assessing systematic error statistical differences occurred in measuring teeth 13, 14, 15, 23, 33, 35, 43 and 44 (Table 1).

In comparing the measuring instruments it was noted that the mesiodistal measurements of teeth 13 , $14,23,33$ and 35 were statistically significantly higher for measurements carried out by the O3d software system compared with a digital caliper (Table 1). The values for required space obtained by applying the regression equation were larger than the sum of the measurements of the premolars and canines on the plaster casts (mean of $3.35 \mathrm{~mm}$ for the maxillary arch and 2.84 $\mathrm{mm}$ for the mandibular arch, and digital casts (mean of $1.11 \mathrm{~mm}$ for the maxillary arch and $0.72 \mathrm{~mm}$ for the mandibular arch). Statistically significant differences were found in the measurements performed in all segments of the dental arch (Table 2).

\section{DISCUSSION}

The measurements of dental sizes obtained both by caliper and by the O3d system presented excellent intraexaminer reliability, established by the correlation $(\mathrm{r})$, which ranged from 0.87 to 0.99 for the caliper and 0.96 to 0.99 for the O3d System (Table 1). A similar intraexaminer reliability - found for both the plaster and digital casts - was reported by Quimby et $\mathrm{al}^{8}$. However, Dalstra and Melsen ${ }^{14}$, after measuring the maxillary right central incisor and first molar on the right side, reported that the intraexaminer variation was lower for the measurements performed on digital casts. Moreover, El-Zanaty et $\mathrm{a}^{15}$ found little correlation between the two methods and attributed the error to (a) difficulties in accurately identifying the contact points and (b) lack of experience of the examiner to conduct measurements on three-dimensional computer images. Random error was not noted in the measurements performed with a caliper. 
Table 1 - Means, standard deviations (SD) and differences (dif) between the first and second mesiodistal measurements of the teeth, in millimeters. Random error (Dahlberg's Formula), systematic error ( $p<0.05$ ), correlation ( $r$ ) obtained from plaster and digital casts and comparison between methods (ANOVA: $p<0.05$ )

\begin{tabular}{|c|c|c|c|c|c|c|c|c|c|c|c|c|c|c|}
\hline \multirow[t]{2}{*}{ Teeth } & \multicolumn{6}{|c|}{ Caliper } & \multicolumn{6}{|c|}{ O3d } & \multicolumn{2}{|c|}{ Caliper } \\
\hline & mean & SD & dif. & Dahlberg & p & $r$ & mean & SD & dif. & Dahlberg & $\mathbf{p}$ & $r$ & dif. & ANOVA \\
\hline 15 & 5.69 & 0.46 & -0.02 & 0.06 & 0.28 & 0.98 & 6.47 & 0.50 & 0.01 & 0.09 & 0.57 & 0.99 & -0.78 & 0.31 \\
\hline 14 & 5.83 & 0.48 & 0.01 & 0.04 & 0.18 & 0.99 & 6.59 & 0.34 & -0.08 & 0.14 & $0.02^{*}$ & 0.99 & -0.77 & $0.01^{*}$ \\
\hline 13 & 7.17 & 0.48 & -0.04 & 0.08 & 0.10 & 0.97 & 7.49 & 0.69 & -0.17 & 0.27 & $0.01^{*}$ & 0.97 & -0.32 & $0.05^{*}$ \\
\hline 23 & 7.09 & 0.46 & -0.01 & 0.06 & 0.57 & 0.98 & 7.63 & 0.69 & -0.16 & 0.29 & $0.04^{\star}$ & 0.96 & -0.54 & $0.05^{\star}$ \\
\hline 24 & 5.85 & 0.52 & -0.06 & 0.07 & $0.00^{*}$ & 0.98 & 6.76 & 0.50 & -0.05 & 0.15 & 0.22 & 0.99 & -0.92 & 0.91 \\
\hline 25 & 5.62 & 0.52 & -0.03 & 0.06 & 0.11 & 0.98 & 6.44 & 0.41 & 0.00 & 0.11 & 0.98 & 0.99 & -0.81 & 0.49 \\
\hline 35 & 6.25 & 0.57 & 0.01 & 0.05 & 0.34 & 0.99 & 7.10 & 0.44 & -0.09 & 0.14 & $0.02^{*}$ & 0.99 & -0.85 & $0.01^{*}$ \\
\hline 34 & 6.20 & 0.52 & -0.05 & 0.15 & 0.18 & 0.92 & 6.87 & 0.53 & -0.06 & 0.16 & 0.21 & 0.98 & -0.67 & 0.91 \\
\hline 33 & 6.35 & 0.56 & 0.00 & 0.05 & 0.98 & 0.99 & 6.77 & 0.61 & -0.20 & 0.29 & $0.01^{*}$ & 0.96 & -0.43 & $0.03^{*}$ \\
\hline 32 & 5.72 & 0.41 & -0.02 & 0.06 & 0.17 & 0.98 & 5.75 & 0.42 & -0.04 & 0.15 & 0.35 & 0.98 & -0.03 & 0.60 \\
\hline 31 & 5.31 & 0.35 & -0.03 & 0.14 & 0.48 & 0.87 & 5.09 & 0.42 & -0.06 & 0.14 & 0.14 & 0.98 & 0.21 & 0.53 \\
\hline 41 & 5.27 & 0.32 & 0.00 & 0.05 & 0.85 & 0.98 & 5.16 & 0.35 & -0.05 & 0.19 & 0.47 & 0.96 & 0.11 & 0.41 \\
\hline 42 & 5.67 & 0.44 & 0.01 & 0.04 & 0.61 & 0.91 & 5.60 & 0.40 & -0.04 & 0.13 & 0.38 & 0.98 & 0.06 & 0.28 \\
\hline 43 & 6.25 & 0.49 & -0.05 & 0.09 & 0.03 & 0.97 & 6.45 & 0.60 & -0.08 & 0.16 & $0.07^{*}$ & 0.98 & -0.20 & 0.39 \\
\hline 44 & 6.05 & 0.59 & -0.01 & 0.09 & 0.76 & 0.97 & 6.91 & 0.51 & -0.06 & 0.12 & $0.05^{*}$ & 0.99 & -0.85 & 0.12 \\
\hline 45 & 6.18 & 0.46 & -0.01 & 0.06 & 0.62 & 0.98 & 7.06 & 0.49 & -0.03 & 0.13 & 0.53 & 0.99 & -0.88 & 0.62 \\
\hline
\end{tabular}

* Statistical significance.

Table 2 - Measurement values ( $\mathrm{mm}$ ) of the required space (RS) obtained by Tanaka and Johnston's regression equation, existing space (ES), difference between the two (RS-ES) and comparison between the methods (Anova: $p<0.05$ ).

\begin{tabular}{|c|c|c|c|c|c|c|c|c|}
\hline \multirow{2}{*}{ Arch } & \multirow{2}{*}{ Measurements } & \multirow{2}{*}{ Side } & \multicolumn{2}{|c|}{ Caliper } & \multicolumn{2}{|c|}{ O3d } & \multicolumn{2}{|c|}{ Caliper } \\
\hline & & & mean & SD & mean & SD & dif. & ANOVA \\
\hline \multirow{5}{*}{ Superior } & RS & \multirow[t]{3}{*}{ Right } & 21.98 & 0.68 & 21.81 & 0.67 & 0.18 & $0.02^{*}$ \\
\hline & ES & & 18.68 & 1.25 & 20.55 & 1.24 & -1.87 & $0.00 *$ \\
\hline & RS-ES & & 3.30 & 0.82 & 1.25 & 0.95 & 2.05 & $0.00 *$ \\
\hline & ES & \multirow[t]{2}{*}{ Left } & 18.55 & 1.33 & 20.82 & 1.24 & -2.27 & $0.00 *$ \\
\hline & RS-ES & & 3.43 & 0.98 & 0.98 & 0.96 & 2.45 & $0.00 *$ \\
\hline \multirow{5}{*}{ Inferior } & RS & \multirow{3}{*}{ Right } & 21.48 & 0.68 & 21.31 & 0.67 & 0.18 & $0.02^{*}$ \\
\hline & ES & & 18.49 & 1.35 & 20.42 & 1.39 & -1.93 & $0.00^{*}$ \\
\hline & RS-ES & & 2.99 & 0.90 & 0.89 & 0.96 & 2.11 & $0.00 *$ \\
\hline & ES & \multirow[t]{2}{*}{ Left } & 18.79 & 1.47 & 20.74 & 1.37 & -1.95 & $0.00 *$ \\
\hline & RS-ES & & 2.69 & 1.03 & 0.56 & 1.01 & 2.12 & $0.00 *$ \\
\hline
\end{tabular}

* Statistical significance

However, in the measurements carried out with the O3d System, random error was found in teeth 13, 23 and 33, which can be explained by a difficulty in determining the angle between the proximal surfaces and the cusps as reference for the largest mesiodistal diameter in three-dimensional images.

The mean value of the differences observed between the first and second measurement of the size of the teeth ranged from 0.00 to $0.06 \mathrm{~mm}$ on the plaster casts and from 0.01 to $0.20 \mathrm{~mm}$ on the digital casts (Table 1). These values have no clinical relevance as they are below the acceptable values, i.e., $0.20 \mathrm{~mm}^{16}$ or $30 \mathrm{~mm} .{ }^{17}$

Despite the excellent intraexaminer reliability of the measurements carried out with the O3d system, systematic error was present in teeth $13,14,15,23$, 33, 35 and 43. The error found in the canines was 
probably due to the position of these teeth, i.e., on the curvature of the dental arch, thereby hindering the movement of the digitized model in the program and the identification of reference points used to perform the measurements.

While performing the measurements, it was noted that the tool used to locate the first reference point was similar to an arrowhead while the second point was defined by a tool shaped like a filled circle, which is less accurate. The points are important in setting the distance that must be measured by the program, which may have affected the measurements of the premolars.

In comparing the measurements obtained with the two instruments, digital caliper and O3d System, it was observed that the values yielded by the latter were higher for all teeth except teeth 31, 41 and 42, where the difference between measurements was very low, ranging from 0.06 to $0.21 \mathrm{~mm}$. The results of this study do not corroborate the findings of Santoro et $\mathrm{al}^{6}$ and Dalstra and Melsen, ${ }^{14}$ who found higher values for the teeth measured with the caliper, and Aguiar and Freitas ${ }^{18}$ and Redlich et $\mathrm{al},{ }^{12}$ in whose research the tooth sizes were underestimated for both dental arches in the measurements performed on digital casts. Keating et $\mathrm{al}^{3}$ and Jedlinska ${ }^{19}$ reported that the measurements obtained with a digital caliper on plaster and digital casts were similar.

In applying Tanaka and Johnston's regression equations to each side of the maxillary arch $[\mathrm{Y}=11+0.5(\mathrm{X})]$ and mandibular $\operatorname{arch}[\mathrm{Y}=10.5+0.5$ $(\mathrm{X})$ ] using the sum of the four erupted permanent mandibular incisors $(\mathrm{X})$ to predict the sum of the non-erupted canines and premolars $(\mathrm{Y})$, it was noted that the predicted spaces were larger than the spaces actually present in the arches. A statistically significant difference was observed in all segments of both arches. Due to the fact that the measurements performed on the digital casts yielded larger values than the measurements obtained from the plaster casts, the difference found by the O3d System between the required space and the existing space were lower than those obtained by the caliper. Thus, in both the plaster and digital casts, the space predicted by Tanaka and Johnston's equation overestimated the size of the premolars and canines in both arches, corroborating the findings of Bishara and Jakobsen ${ }^{20}$ nikTahere et al, ${ }^{21}$ Arslan et $a 1,{ }^{22}$ and unlike Melgaço et $a l,{ }^{23}$ who found underestimated values, although with no clinical significance.

The measurements obtained from the digital casts in this study were reproducible, although some difficulties were encountered during measuring. The viewing of contact points, the excessive brightness in the models, the determination of reference points with the locating tool in the shape of a filled circle and the frequent failure in saving the data are some of the issues that need to be addressed by those who use the digital measurement analysis. This measuring instrument proved to be a promising tool in the analysis of dental casts. The system, however, calls for improvement while professionals must be trained to ensure proper use.

\section{CONCLUSIONS}

Based on the method employed in this study, one can conclude that dental size measurements showed good reproducibility in both plaster and digital casts. However, the measurements taken by the O3d software system proved superior to those obtained by caliper, and Tanaka and Johnston's equation ${ }^{2}$ overestimated the sizes of premolar and canine teeth in the maxillary and mandibular arches with both measurement instruments. 


\section{REFERENCES}

1. Alhaija ESJ, Qudeimat, MA. Mixed dentition space analysis in a Jordanian population: comparison of two methods. Int J Paediatr Dent. 2006:16(2):104-10

2. Tanaka MM, Johnston LE. The prediction of the size of unerupted canines and premolars in a contemporary orthodontic population. J Am Dent Assoc. 1974;88(4):798-801.

3. Keating AP, Knox J, Bibb R, Zhurov Al. A comparison of plaster, digital and reconstructed study model accuracy. J Orthod. 2008;35(3):191-201.

4. Redmond WR. Digital models: a new diagnostic tool. J Clin Orthod. 2001:35(6):386-7

5. Paredes V, Gandia JL, Cibrián R. Digital diagnosis records in orthodontics. An overview. Med Oral Patol Oral Cir Bucal. 2006;11(1):e88-93.

6. Santoro M, Galkin S, Teredesai M, Nicolay OF, Cangialosi TJ. Comparison of measurements made on digital and plaster models. Am J Orthod Dentofacial Orthop. 2003:124(1):101-5.

7. Whetten JL, Williamson PC, Heo G, Varnhagen C, Major PW. Variations in orthodontic treatment planning decisions of Class II patients between virtual 3-dimensional models and traditional plaster study models. Am J Orthod Dentofacial Orthop. 2006:130(4):485-91.

8. Quimby ML, Vig KW, Rashid GR, Firestone AR. The accuracy and reliability of measurements made on computer-based digital models. Angle Orthod. 2004:74(3):298-303

9. Zilberman O. Huggare JA, Parikakis KA. Evaluation of the validity of tooth size and arch width measurements using conventional and threedimensional virtual orthodontic models. Angle Orthod. 2003;73(3):301-6.

10. Leifert MF, Leifert MM, Efstratiadis SS, Cangialosi TJ. Comparison of space analysis evaluations with digital models and plaster dental casts. Am J Orthod Dentofacial Orthop. 2009:136(1):16.e1-4

11. Mayers M, Firestone AR, Rashid R, Vig KW. Comparison of peer assessment rating (PAR) index scores of plaster and computer-based digital models. Am J Orthod Dentofacial Orthop. 2005:128(4):431-4.
12. Redlich $M$, Weinstock $T$, Abed $Y$, Schneor $R$, Holdstein $Y$, Fischer $A$. A new system for scanning, measuring and analyzing dental casts based on a 3D holographic sensor. Orthod Craniofac Res. 2008;11(2):90-5.

13. Houston WJB. The analysis of error in orthodontics measurements. Am J Orthod. 1983:83(5):382-90.

14. Dalstra M, Melsen B. From alginate impression to digital virtual models accuracy and reproducibility. J Orthod. 2009;36(1):36-41

15. El-Zanaty HM, El-Beialy AR, Abou El-Ezz AM, Attia KH, El-Bialy AR, Mostafa YA. Three-dimensional dental measurements: an alternative to plaster models. Am J Orthod Dentofacial Orthop. 2010;137(2):259-65.

16. Schirmer UR, Wiltshire WA. Manual and computer-aided apace analysis: a comparative study. Am J Orthod Dentofacial Orthop. 1997:112(6):676-80

17. Hirogaki Y, Sohmura T, Satoh H, Takahashi J, Takada K. Complete 3-D reconstruction of dental cast shape using perceptual grouping. IEEE Trans Med Imaging. 2001;20(10):1093-101

18. Aguiar RM, Freitas BV. Confiabilidade da análise de Moyers em indivíduos de São Luís-MA. Ortho Sci Orthod Sci Pract. 2008;1(2):147-52.

19. Jedlinska A. The comparison analysis of the line measurements between plaster and virtual orthodontic 3D models. Ann Acad Med Stetin. 2008;54(2):106-13.

20. Bishara SE, Jakobson JR. Comparison of two non radiographic methods of predicting permanent tooth size in the mixed dentition. Am J Orthod Dentofacial Orthop. 1998:114(5):573-6

21. nikTahere H, Majid S, Fateme M, Kharazi F, Javad M. Predicting the size of unerupted canines and premolars of the maxillary and mandibular quadrants in an Iranian population. J Clin Pediatr Dent. 2007:32(1):43-7.

22. Arslan SG, Dildes, N, Kama JD, Genc C. Mixed-dentition analysis in a Turkish population. World J Orthod. 2009;10(2):135-40.

23. Melgaço CA, Araújo MT, Ruellas AC. Applicability of three tooth size prediction methods for white Brasilians. Angle Orthod. 2006:76(4):644-9. 